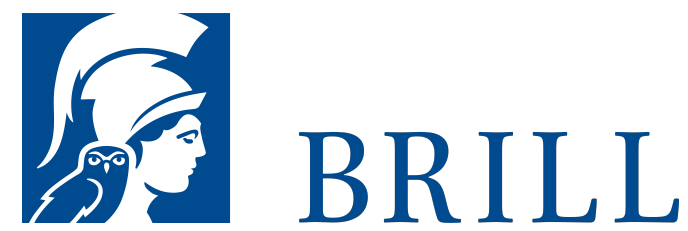

\title{
Der Sündenfall der Nachahmung
}

Zum Problem der Mittelbarkeit im Werk Ralph Waldo Emersons

Author:Jan Stievermann

Ralph Waldo Emerson (1803-82) gilt als einer der größten amerikanischen Literaten und Philosophen. Erstmals in deutscher Sprache wird hier sein gesamtes Prosawerk (inklusive der erst jüngst edierten Later Lectures) umfassend untersucht. In einer kritischen Neulektüre der Predigten, Vorlesungen und Essays wird die denkerische Entwicklung Emersons gedeutet unter dem Gesichtspunkt dessen anhaltender Auseinandersetzung mit dem für die Romantik so zentralen Problem der Mittelbarkeit bzw. der kulturellen Vermitteltheit möglicher Formen individueller Erfahrung - insbesondere auch der religiösen -, der Weltdeutung und des Selbstausdrucks. Nachgezeichnet wird diese Auseinandersetzung anhand Emersons wiederholter theoretischer Umdeutungen des Prinzips der Nachahmung normativer Modelle als zentralem Mechanismus der kulturellen Vermittlung oder Traditionsbildung, der sozialpraktischen wie religiösen Orientierung und nicht zuletzt auch als Verfahren der Literaturproduktion. Dabei wird stets auch nach der Übersetzung dieser wechselnden Interpretationen des imitatioPrinzips in die (inter-)textuelle Praxis Emersons gefragt.

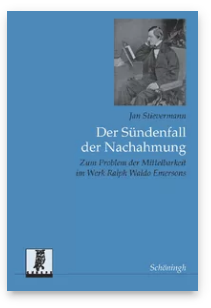

Pages: 953

Seiten

Language:

German

Subjects:

English \&

Anglophone,

Literature and

Cultural Studies

Publisher: Brill |

Schöningh

Series:

Beiträge zur

englischen und

amerikanischen

Literatur,

Volume: 24

E-Book (PDF)

Released online:

11 Jul 2019

ISBN: $978-3^{-}$

657-75618-6

List price

USD.D \$180.00

Paperback

Publication date: 22 Feb 2007

ISBN: $978-3^{-}$ 506-75618-3

List price USD \$180.00 
For more information see brill.com

Order information: Order online at brill.com +44330 333 0049 | customerservices@brill.com Submission information: brill.com/authors

Titles published by Brill | Fink, Brill | mentis or Brill | Schöningh: +49(o)715413279216| brill@brocom.de 